\title{
Germanica
}

\section{Handlinien. Datumsgrenzen. Über zwei Gedichte von Durs Grünbein}

Lignes de la main. Une date et ses limites. Sur deux poèmes de Durs Grünbein

Hermann Wallmann

\section{(2) OpenEdition}

Journals

Édition électronique

URL : http://journals.openedition.org/germanica/1484

DOI : 10.4000/germanica. 1484

ISSN : 2107-0784

Éditeur

Université de Lille

Édition imprimée

Date de publication : 30 décembre 1997

Pagination : 157-162

ISBN : 977098426320321

ISSN : 0984-2632

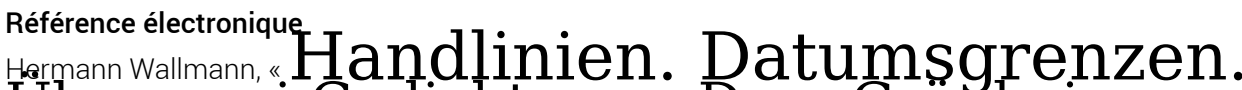
Uber zwei Gedichte von Durs Grünbein $»$, Germanica

[Online], 21 | 1997, Online erschienen am: 08 Juni 2012, abgerufen am 06 Oktober 2020. URL : http:// journals.openedition.org/germanica/1484; DOI : https://doi.org/10.4000/germanica.1484

Ce document a été généré automatiquement le 6 octobre 2020.

(c) Tous droits réservés 


\title{
Handlinien. Datumsgrenzen. Über zwei Gedichte von Durs Grünbein ${ }^{1}$
}

Lignes de la main. Une date et ses limites. Sur deux poèmes de Durs Grünbein

\author{
Hermann Wallmann
}

«Schon eine Hand genügt, / Frühe Höhlenbilder in ihren Linien zu finden », sagt das eine Gedicht, und das andere liest in solchen Höhlenbildern die Falten einer Stirn, auf der die Angst, die das eine Gedicht in der Hand gelesen hat, zu einer Legende geworden ist, wie sie entweder das Leben eines Heiligen oder Narren in Lettern verwandelt oder die Piktogramme einer Landkarte ins Leben zurückholt. Hier aber ist die Legende vom wortlosen Kapieren (vgl.lat. caput) zitiert, als ob es sein Gegenteil gäbe, mit anderen Worten : Kann Stille schwitzen ? - : «Was war die Zukunft / Die/aus den Handlinien folgte, Glück oder Unglück / Gegen den Terror der Poren » - der ja wohl nur als Genitivmetapher Sinn macht ? - « in denen der Schweiß stand / Wie die Legende vom stillen Begreifen auf einer Stirn», fragt das andere Gedicht in erlebter Rede, die transparent bleibt für das Imperfekt und mithin ostentativ dem Präsens wie dem Futur II enträt: Was uns blüht, sind Höhlenbilder. Wenn Handlinien an Höhlenbilder gemahnen oder an den Blocksatz der Legenda aurea oder an die Matrix, die eine Stirn entzifferbar macht, dann ist ein Tertium comparationis die Textur des Gedichts, das auf dem Papier transpiriert, ein troglodytischesn Sprachgitter, das unter der Stablampe, nein der Stirnlampe des (freihändigen !) Speläologen dunkel zu glänzen beginnt, engbedruckt ist die Hand des Dichters, aber zurück zu den Anfängen, den Luftwurzeln, ich habe in Durs Grünbeins Gedichten geblättert, ich habe mit ihnen getan, was ich wollte, eine Mischung aus Absence und Bibelstechen, ich weiß nicht, ist es die Alliteration, die den Ausschlag gegeben hat, Mißklang und Mantegna, vielleicht Mißklang, vielleicht Mantegna, vielleicht Mißklang, weil ich Republikaner ihn lieber selbst 
herausgehört hätte, may be Mantegna, weil der mich an Det malede vaerelse von Inger Christensen erinnert hat, ich sage nur Orpheus. Ach, und Peter Bichseis Kindergeschichte vom Mann, der nichts mehr wissen wollte, und unlängst, auf dem Rücken meiner Cigarilloschachtel dieser mundgeblasene, zeilengebrochene Satz, halb Anmaßung, halb Demut: «Ich finde mich / mit nichts ab ! » Im Zweifelsfall hat Durs Grünbein nicht das eine Körpermassiv, den behexten Stallknecht von Hans Baidung Grien, vor Augen gehabt, sondern das andere, die Beweinung Christi in der Pinacoteca di Brera, denn erstem hat es die Schuhe nicht ausgezogen, während letzterer seine nackten Füße mit ihren durchlöcherten Sohlen, den Falten und Fußlinien, dem Betrachter entgegenreckt. Die geschundene Epidermis, unverklärt gemalt in ihrer grausamen Kraftlosigkeit, bekommt zusätzlich Höhe und Tiefe durch die Rasterung in eben derjenigen Frankfurter Allgemeinen Zeitung von den Iden des März 1997 (neunundvierzigster Geburtstag meines zweieiigen Zwillingsbruders!), die in der Wochenendbeilage «Bilder und Zeiten » (Plural!) von Klaus Fußmann einen Aufsatz über Die ewigen Jagdgründe der Kunst enthält - mit der Reproduktion eines Fotos aus der Bilderhöhle von Chauvet und dem Untertitel Unterwegs $z u$ den ersten Menschen und der ersten Moderne, modern ist nicht nur ein Adjektiv. (Bei Mantegna hat Christus die Hände zu schlaffen Fäusten geballt, welkenden gelbroten Rosen, die Grünbein in seinem Gedicht aufblättert wie ein vorsokratischer Enkel die Hand des Großvaters, in der er den Groschen vermutet, der in der anderen längst zu schmelzen begonnen hat.)

2 Nichts wollte ich von Durs Grünbein mehr wissen, und ich habe mich jetzt auch entschlossen, kein weiteres Gedicht noch einen kürzeren Aufsatz, keine fernere Dankrede noch das Gespräch über die Zone, den Hund und die Knochen zu lesen oder wiederzulesen oder widerzulesen. (Gottfried Benn - wer je bestimmte Berlinismen von ihm hörte, wird es schwer vergessen - hat vom «Schlach » gesprochen, der alles löst : Der Glasbläser hat keinen Einfluß mehr darauf, ob seine Vase auf einem schellackpolierten Mahagonitisch steht oder im Besenschrank einer Krebsbaracke, ob eine Frau in ihr wie Stunden die Astern ordnet oder Pfennige sammelt für die gläsernen Schuhe). Denn daß einem eine Schweißlegende - zwei Quartette, zwei Terzette - auf der Stirn glänzt, ein Menetekel aus Wasser und Salz, hängt damit zusammen, daß man mit dem Begreifen ebensowenig gerechnet hat wie ein Höhlenforscher mit dem Flor, dem Licht, dem Himmel, den goldenen Herden, die aus dem Kalksandstein der Höhle von Chauvet oder Cosquer hervortreten, signiert von lauter linken Händen, die John Berger so vorgekommen sind, als wären sie mit Schablonen in Ocker gemalt worden, stand am 22. Februar 1997 auf der holzhaltigen Seite 3 von «Zeit und Bild» (Singular!) zu lesen, der Wochenendbeilage der Frankfurter Rundschau - exakt eine Woche bevor am gleichen Ort Durs Grünbein mit HeinzNorbert Jaucks den «traurigen Marsch der Epigonen » ausgezählt hat, um coram publico sein Verhältnis mit der bildenden Kunst aufzubieten. Und so werden sie plötzlichdurchsichtig füreinander, diese beiden 
Zeitungsseiten, und mit Mantegna, das ist so abwegig nicht. Ob Ruß oder Druckerschwärze oder Handlinien, die Höhlenzeichnung ist so erhaben wie die «dunkele » Kammer des Gedichts tief, Mantegna hat nicht Wände bemalt, vielmehr Zimmer gemalt, Handlinien sind Höhenlinien, die Gräben submarin, die Gebirge überirdisch, blau und rauschbereit das eine wie das andere, der Horizont hat sieben Häute. Schon eine Hand genüge, singt und sagt Durs Grünbein im vorletzten Satz seines Mißklangs, was heißt und heischt das anderes als : Omnia mea mecum porto, meine Hand ist mein Handbuch, das ich auch im Finstern (vgl. lat. finis terrae) lesen kann, im Halbschlaf, ich gehe von meinen Beständen aus, mein Gedicht ist mein Messer, das weder eine kannibalistische Klinge hat, weder einen humanistischen Griff, nulla dies (irae) sine linea. Womit auch schon das zweite Gedicht auf dem Tisch liegt, an dem ein Kalauer sitzt, im Hinterkopf den Bericht an die Akademie nicht der redenden, der bildenden Künste. Er studiert seinen leeren Handteller, als wäre er, sit venia verbo, die Frikadelle, der gelbrote Fleischballen, den er soeben von ihm gegessen hat - mit so nekrophilem wie vergeßlichem wie taubstummem Besteck. Wie lange, bis die Vorhersagen stimmen, werden Hände gelesen, was waren Tonleitern, was Herzrhythmen, was Pausen, die aus den Handlinien folgten, Glück ist die gewaschene eine, Unglück die waschende andere Hand, warum aber der Verdacht gegen die Verklärung, das Votum für Dissonanzen ? Das erste Wort der ersten Zeile des ersten Gedichts ist ein fragendes «wie», das erste der letzten des zweiten ein antwortendes : Als würden Vergleiche uns weniger hinfällig machen ! Durs Grünbein spricht über seine Hände, seine Gedichte, über seine gedichteten Hände wie ein Tourist über Touristen, ich ist ein anderer, das war einmal, das war weiland, als das Wünschen noch geholfen hat, die Leiche in der Morgue, das bin nicht ich : Aber auch Gottfried Benn hat ja nicht ohne Ende (vgl. lat. usque ad finem) sämtliche seiner Astern ersoffenen Bierfahrern zwischen die Zähne (Sprache!) geklemmt, ins Gehirn (Form !) gleiten lassen und zwischen Holzwolle in die Brusthöhle (Inhalt!) gepackt, still, Eurydike, dreh dich nicht um, er könnte dich sehen.

\section{NOTES}

1. Mißklang aus: Falten und Fallen, Frankfurt am Main 1994, S.96, und Mantegna vielleicht aus : Akzente 6/96, S. 481. 


\section{RÉSUMÉS}

Nicht wie die betenden Hände von Albrecht Dürer passen die Gedichte Mantegna vielleicht und Mißklang von Durs Grünbein wie Faust IIaufs Auge, sondern wie die Hand des Dichters auf die Hand des Lesers. Was aber, hätte Heraklit gefragt, was von den beiden Gedichten ist das eine, das nicht weiß, was das andere tut ? Oder umgekehrt : Das eine Gedicht ist die rechte Hand, die man ungläubig auf den Spiegel gelegt hat, das andere die unerreichbare linke, die erste von Herzblut warm ?

Ce n'est pas à la manière des mains jointes pour la prière d'Albrecht Dürer que les poèmes Mantegna vielleicht (Mantegna peut-être) et Mißklang (Dissonance) semblent devoir frapper l'œil du lecteur, comme le Second Faust;ce serait plutôt la main du poète qui se pose naturellement sur celle du lecteur. Mais, aurait demandé Heraclite, lequel de ces deux poèmes est celui qui ne sait pas ce que fait l'autre? Ou inversement : l'un des poèmes est la main droite, que l'on a posée incrédule sur le miroir, l'autre est l'inaccessible main gauche, la première à être réchauffée du sang venu du cœur. 